\title{
Um relato sobre estratégias de motivação e ensino de lógica de programação para e por mulheres
}

\author{
Camila Sass $^{1}$, Camila Kanashiro ${ }^{1}$, Érika Yahata ${ }^{1}$, Gabriela Nocete ${ }^{1}$, Julia Baldi ${ }^{1}$, \\ Lara Tenore $^{1}$, Natália Santana ${ }^{1}$, Thais Ribeiro ${ }^{1}$, Carla Rodriguez ${ }^{2}$, Cristiane Sato ${ }^{2}$, \\ Denise Goya $^{2}$, Mirtha Venero ${ }^{2}$, Rafaela V. Rocha ${ }^{2}$ \\ ${ }^{1}$ Universidade Federal do ABC (UFABC) \\ ${ }^{2}$ Centro de Matemática, Computação e Cognição (CMCC) \\ Campus Santo André - Avenida dos Estados, 5001 - Bairro Santa Terezinha \\ Santo André - SP - Brasil - CEP: 09210-580 \\ ${ }^{1}$ \{camila.sass, yukari.kanashiro, e.yahata, nss_gabi, j.baldi, \\ laratenore, n.santana, tha.sribeiro\} daluno.ufabc.edu.br, \\ ${ }^{2}\{$ c.rodriguez, c.sato, denise.goya, mirtha.lina, \\ rafaela.rocha\} @ufabc.edu.br
}

\begin{abstract}
The low number of women in Computing courses is a problem addressed worldwide. However, local initiatives are needed that require the participation of the community of interest. In this context, this article reports a project that aims to apply different strategies to motivate and teach programming logic to and by women. The methodology includes three processes: research (understanding factors that discourage girls from computing), dissemination, motivation and teaching programming logic in courses for women. In this paper, the actions in progress are presented, that aim to contribute to the increase of the number of women in the course, as well as their first results.
\end{abstract}

Resumo. A baixa representatividade feminina nos cursos de Computação é um problema abordado mundialmente. Entretanto, são necessárias iniciativas locais que precisam da participação da comunidade de interesse. Dessa forma, este artigo relata um projeto que visa aplicar diferentes estratégias para motivar e ensinar lógica de programação para e por mulheres. A metodologia aborda três processos: pesquisa (compreensão dos fatores que afastam meninas da computação), divulgação, motivação e ensino de lógica de programação em cursos para mulheres. No artigo são apresentadas as ações em andamento que visam contribuir para o aumento do número de mulheres na área, bem como seus primeiros resultados.

\section{Introdução}

Segundo o relatório da UNESCO (2018) sobre educação de meninas e mulheres em STEM (Science, Technology, Engineering and Mathematics), as mulheres representam apenas $35 \%$ de todos os estudantes matriculados nos campos de estudo relacionados. A diferença quantitativa entre mulheres e homens em cursos de STEM é tão relevante mundialmente que é contemplada na Agenda 2030 para o Desenvolvimento Sustentável da ONU. Em particular nos objetivos sobre educação inclusiva e equitativa de qualidade e aprendizagem ao longo da vida (ODS 4), e sobre a igualdade de gênero e empoderamento das meninas e mulheres (ODS 5). Como citado no relatório da UNESCO, os sistemas educacionais e as escolas exercem um papel importante em 
VII Congresso Brasileiro de Informática na Educação (CBIE 2018)

Anais dos Workshops do VII Congresso Brasileiro de Informática na Educação (WCBIE 2018)

estimular o interesse das meninas em disciplinas de STEM, bem como em oferecer oportunidades para que elas acessem e se beneficiem de uma educação de qualidade na área. Por isso, as iniciativas para engajar meninas a seguirem essas carreiras devem ser promovidas pela sociedade em geral e escolas desde o ensino básico até o nível superior.

No Brasil, segundo dados do Censo da Educação Superior 2016 (Inep), no curso de Ciência da Computação, as mulheres representam cerca de $20 \%$ dos estudantes, sendo este o segundo curso com menor porcentagem de mulheres após Engenharia Mecânica. Além disso, a pesquisa realizada por Maia (2016) revelou que, entre os anos 2000 e 2013, a porcentagem de mulheres concluintes nos cursos de Computação foi em média de $17 \%$ e esse percentual decresce com pequenas oscilações. Conscientes dessa baixa representatividade feminina, muitas instituições estão criando e apoiando projetos para reverter esse cenário. Entre elas, destaca-se a Sociedade Brasileira de Computação (SBC), que em 2015 institucionalizou o Programa Meninas Digitais, criado em 2011 a partir de discussões no WIT - Women in Information Technology, evento satélite do Congresso da SBC. O programa tem como objetivo motivar alunas do ensino médio/tecnológico, ou nos anos finais do ensino fundamental, a desenvolver conhecimento nas áreas da Computação e Tecnologias da Informação e Comunicação (Maciel e Bim 2017). Ele inclui diversas ações como palestras, minicursos, oficinas e mais de 50 projetos parceiros no país. O WIT também tem promovido trabalhos com análises sobre a presença de mulheres em cursos ligados à Computação no ensino superior brasileiro (Nunes et al. 2016, Holanda et al. 2017, Nakamura et al. 2017, Monteiro et al. 2017). As questões de gênero do Brasil também têm sido discutidas no LAWCC - Congresso da Mulher Latino-americana em Computação (Monard e Fortes 2013, Bim et al. 2107, Nakamura et al. 2017, de Freitas et al. 2017). Uma das principais causas para a baixa adesão feminina em cursos de STEM são os estereótipos de gênero que associam as mulheres a características como afetividade e delicadeza (Grossi et al. 2016). Por isso, existem vários sites de caráter pessoal, idealizados e desenvolvidos por mulheres, para desmistificar a Computação como uma área de preferência masculina, e.g. PrograMaria, Reprograma, MinasProgramam, MariaLab, Mulheres na Computação.

Este artigo apresenta um projeto voltado para engajar meninas no curso de Ciência da Computação na Universidade Federal do ABC alinhado com os objetivos ODS 4 e 5 . O projeto, nomeado $++C \& \mathrm{TpM}^{1}$ nasceu de um grupo de mulheres com vontade de contribuir para que a igualdade de gênero seja alcançada nessa área. A equipe está composta por oito alunas protagonistas de todas as atividades e cinco docentes que ajudam na orientação e coordenação. $O$ projeto iniciou seus trabalhos no contexto de um edital para a melhoria do ensino, tendo como alvo meninas, com pouco ou nenhum contato com programação, que já haviam ingressado no ensino superior. Contudo, desde o início o grupo identificou como uma necessidade em levar o conhecimento sobre Ciência da Computação para alunas de escolas públicas da região, para que elas possam ter contato com uma área que muito possivelmente desconhecem ou nem ao menos cogitam como uma possibilidade. $\mathrm{O}$ artigo descreve os primeiros resultados de ações em andamento e o impacto dessas ações em meninas que não

\footnotetext{
${ }^{1}$ ++C\&TpM: Desmistificando a Ciência da Computação e as Tecnologias da Informação por e para Mulheres (http://pesquisa.ufabc.edu.br/lirte/ctpm/).
} 
VII Congresso Brasileiro de Informática na Educação (CBIE 2018)

Anais dos Workshops do VII Congresso Brasileiro de Informática na Educação (WCBIE 2018)

cogitavam uma carreira em computação, ou sobre aquelas que apresentavam interesse, mas não se sentiam seguras em segui-la.

\section{O Curso de Ciência da Computação na UFABC e o ++C\&TpM}

A UFABC oferece o curso de Bacharelado em Ciência da Computação (BCC), com duração mínima de quatro anos. Entretanto, para serem admitidas(os) no curso, as(os) discentes devem estar cursando ou já ter cursado o Bacharelado em Ciência e Tecnologia (BC\&T). O BC\&T é um dos dois cursos obrigatórios de ingresso da UFABC, cuja formação em nível de graduação conduz a um diploma com foco na interdisciplinaridade, no diálogo entre as áreas do conhecimento e na flexibilidade curricular (UFABC, 2017). Diferente do sistema educacional tradicional, a estrutura da grade curricular da UFABC é baseada no regime quadrimestral e em um sistema de créditos que permite diferentes organizações curriculares, conforme os interesses das(os) discentes. Ou seja, cada aluna(o) é responsável por se matricular nas disciplinas que tem interesse. No entanto, existem disciplinas obrigatórias em comum para todas(os). Este sistema preserva a ideia de liberdade para a exploração de novos caminhos em todas as atividades acadêmicas, e nele as alunas e os alunos podem optar por um ou vários cursos específicos após o BC\&T.

Segundo os dados da Pró-Reitoria de Planejamento e Desenvolvimento Institucional da $\mathrm{UFABC}^{2}$, o BCC está entre os cinco bacharelados pós BC\&T mais pretendidos. No entanto, dentre todos os cursos específicos ele é um dos de menor proporção na pretensão das mulheres, com 14\%. Além disso, uma pesquisa realizada no CMCC revelou que no $\mathrm{BCC}$ a porcentagem total de mulheres matriculadas é aproximadamente de $18,9 \%$. Por isso, o $++\mathrm{C} \&$ TpM surgiu da necessidade e vontade, de alunas e professoras, de aumentar a quantidade de mulheres no curso e contribuir para um número maior de egressas da UFABC com habilidades para a resolução computacional de problemas.

De acordo com Microsoft Corp (2017), existem cinco pilares que são considerados de maior impacto para o interesse de meninas: (i) modelos femininos reais a quem possam se identificar, (ii) experiências práticas, (iii) encorajamento e mentoria, (iv) compreensão das aplicações práticas e relevância para o futuro e (v) confiança que serão tratadas com igualdade na carreira. Com base nesses pilares, a equipe do projeto, composta por oito alunas do BC\&T e cinco professoras do $\mathrm{BCC}$, identificou como necessário ter três frentes principais de trabalho: i) pesquisa e coleta de dados: sobre o tema das mulheres na tecnologia, dentro e fora da Universidade, para tentar compreender melhor o problema e ter dados ao longo dos anos para identificar se as ações do projeto terão algum impacto; ii) divulgação em redes sociais e site: conteúdos com exemplos de mulheres que atuam e são muito importantes na área de computação, dúvidas que costumam ocorrer sobre a carreira, ações do projeto, entre outras informações. O objetivo dessa frente é proporcionar maior divulgação sobre o tema e a carreira para o público feminino de um ponto de vista feminino; iii) ensino e desenvolvimento de habilidades de lógica de programação em meninas ingressantes na universidade, bem como para meninas das escolas da região. Esta frente foi motivada pela experiência das próprias alunas, pois o início do BCC pode ser bastante difícil para quem não teve nenhum contato com programação antes. Dentro deste contexto, notou-

${ }^{2}$ http://propladi.ufabc.edu.br/images/perfil_aluno/apresentacao 2017.pdf 
VII Congresso Brasileiro de Informática na Educação (CBIE 2018)

Anais dos Workshops do VII Congresso Brasileiro de Informática na Educação (WCBIE 2018)

se que a ação em escolas é muito importante, pois muitas meninas não se vêm atuando nessa área por achar que não possuem inclinação para tal, sendo este um campo masculino. Assim, o curso pode mostrar que elas também podem seguir a carreira na computação, contribuindo para a quebra de estereótipos e aumento do número de meninas ingressantes que pretendam cursar Ciência da Computação.

\section{Metodologia e Ações em Andamento do ++C\&TpM}

\subsection{Pesquisa}

$\mathrm{Na}$ primeira frente de trabalho do projeto buscou-se avaliar possíveis causas que influenciam a baixa adesão de mulheres no curso de BCC. Um dos parâmetros analisados foi o desempenho acadêmico das discentes do sexo feminino nas disciplinas básicas (obrigatórias do BC\&T), que lidam com o pensamento computacional e lógica de programação: Bases Computacionais da Ciência e Processamento da Informação. Uma das hipóteses levantadas previamente era de que o baixo desempenho das discentes nessas disciplinas poderia levar a um desestímulo, fazendo com que elas desistissem de cursar posteriormente o BCC. Nessas disciplinas, a porcentagem de alunos do sexo masculino nas turmas era de aproximadamente $70 \%$ enquanto o número de alunas era de aproximadamente 30\%. Apesar dessa diferença, a análise do desempenho nos últimos cinco anos revelou que os conceitos obtidos pelas mulheres foram similares aos dos homens, o que descarta a hipótese anterior. A Figura 1 mostra o desempenho em ambas as matérias nos anos (i) 2016 e (ii) 2017, nos quais os conceitos de " $A$ " a " $D$ " representam aprovação e os conceitos " $F$ " e "O" reprovação por desempenho e frequência, respectivamente.

(i)

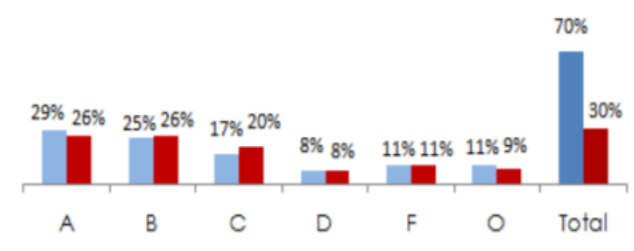

(ii)

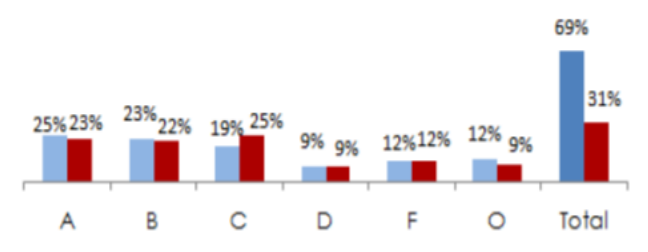

(i)

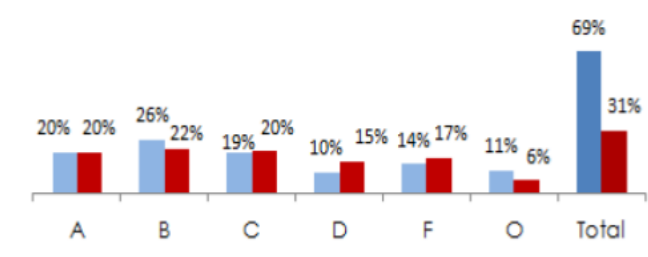

(ii)

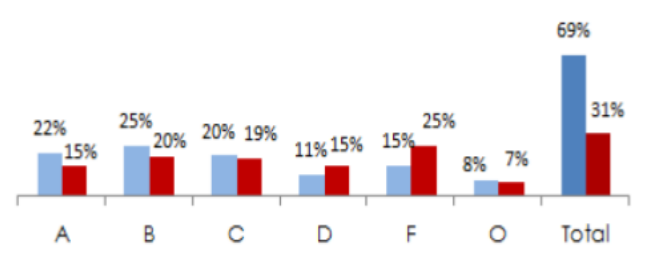

Figura 1. Desempenho de discentes nas disciplinas de Bases Computacionais da Ciência (esquerda) e Processamento da Informação (direita), por sexo (feminino em vermelho). Fonte: Pró-Reitoria de Graduação.

Apesar de um desempenho regular, a maior parte das mulheres opta por não seguir para o BCC, o que pode ter influência de outros fatores, como estereótipos de gênero e o próprio ambiente do curso, por ser predominantemente masculino. Além disso, observou-se que a baixa participação feminina não se dá somente no âmbito da graduação, como também no corpo docente do BCC, no qual somente $26,4 \%$ são mulheres. A pesquisa também revelou a baixa participação feminina nas colações de grau do BCC com uma porcentagem de 14,6\%. Conforme mostra a Figura 2, a situação torna-se ainda mais preocupante ao constatar a redução do número de formandas no curso desde 2016 e não ter nenhuma graduada em 2017. 


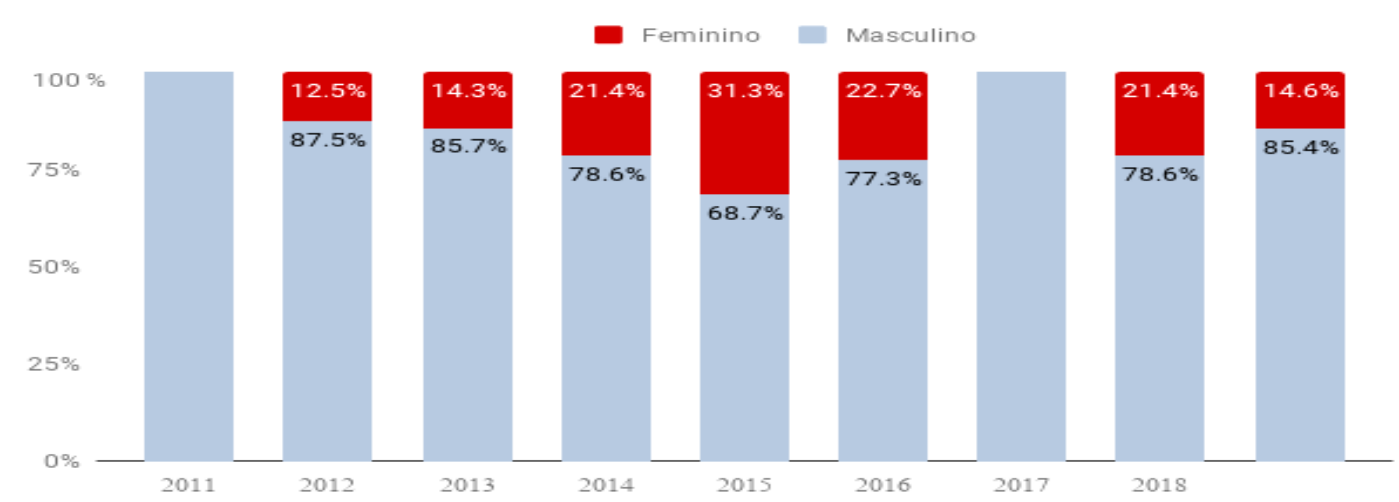

Figura 2. Participação por gênero nas colações de grau do BCC. Fonte: Secretaria acadêmica CMCC.

$\mathrm{O}++\mathrm{C} \& \mathrm{TpM}$ tem como proposta investigar as possíveis causas que influenciam esse cenário, junto com profissionais da área de estudos de questões de gênero, formulando questionários e aplicando-os à comunidade acadêmica. Acredita-se que tendo conhecimento sobre os fatores que desestimulam as mulheres de cursar Ciência da Computação, é possível trabalhar melhor no desenvolvimento de iniciativas para atraílas para a área e diminuir a evasão ao longo da graduação.

\subsection{Divulgação}

$\mathrm{Na}$ era digital e das redes sociais considerou-se imprescindível que o projeto estivesse presente no âmbito digital por meio de um site, um grupo e uma página no Facebook. $\mathrm{O}$ site contém informações gerais sobre o projeto e nele podem ser encontrados conteúdos que são divulgados no Facebook, sendo um local onde essas informações estão melhor organizadas e podem ser facilmente encontradas. Desde o lançamento (90 dias), o site teve 130 usuários, 213 seções (média de $4 \mathrm{~m} 17 \mathrm{~s}$ ) com 839 page views. Também há um grupo fechado no Facebook, administrado por alunas do projeto, que atualmente conta com 159 participantes, todas mulheres. A escolha de ser um grupo só para mulheres foi tomada com base na necessidade de existir um ambiente mais acolhedor, no qual as mulheres pudessem se sentir à vontade para conversar, tirar dúvidas e compartilhar experiências, por exemplo, sendo um contraponto das salas de aula compostas por maioria masculina.

A página no Facebook foi criada para ser um meio de divulgação de atividades do projeto, ações que se alinhem ao tema mulheres na tecnologia e mulheres que fazem a diferença no campo da ciência da computação, uma vez que foi notada a falta de referências femininas nesta área. Este canal também foi visto como necessário uma vez que está presente em uma rede social de amplo uso, sendo possível alcançar também os homens, que são imprescindíveis nesse debate.

Embora o Facebook tenha sido escolhido por tornar a comunicação mais rápida e facilitar o alcance de um número maior de pessoas, notou-se que há uma dificuldade de interação, pois esta tem sido baixa, mesmo no grupo voltado apenas para mulheres. Por isso, outra iniciativa de divulgação realizada foi o Workshop "Mulheres na Computação: os desafios da carreira", durante a IV Semana do CMCC com o tema "Mercado \& Inovação". No encontro, a equipe de alunas apresentou o projeto, os primeiros resultados da pesquisa sobre a representatividade feminina na UFABC e divulgaram as principais ações do grupo. $\mathrm{O}$ Workshop também incluiu outras palestras 
VII Congresso Brasileiro de Informática na Educação (CBIE 2018)

Anais dos Workshops do VII Congresso Brasileiro de Informática na Educação (WCBIE 2018)

sobre representação de gênero nas carreiras de tecnologia. Além disso, as palestrantes se juntaram a outras professoras e alunas convidadas em uma roda de conversa para troca de experiências sobre os desafios das mulheres no mercado de trabalho e na academia.

O Workshop contou com 32 participantes e o público foi incentivado a interagir durante as apresentações, enviando perguntas e respondendo enquetes pelo aplicativo sli.do. As convidadas responderam às perguntas durante a roda de conversa, expondo suas vivências como mulheres inseridas na área de Tecnologia, discutindo sobre estereótipos de gênero e sobre os desafios encontrados ao longo de suas carreiras. Junto com as questões enviadas pelo aplicativo, foram recebidos comentários positivos pela iniciativa do evento, além da manifestação ao vivo de meninas e meninos que se identificaram com o tema.

\subsection{Ensino: Curso de Lógica de Programação e Python}

Com a baixa representatividade feminina apontada pela pesquisa e notando-se a dificuldade nas matérias iniciais da computação, identificou-se a necessidade de apoiar as alunas no primeiro contato com lógica de programação e com uma linguagem de programação, além de incentivar as alunas que já finalizaram as matérias básicas a darem continuidade em seus estudos da área. Para isso, foi projetado um minicurso de nove encontros semanais, de duas horas cada, com o objetivo de propiciar um ambiente de aprendizagem favorável para desenvolver autoconfiança, aumentar a motivação das meninas e quebrar estereótipos sobre a aprendizagem computacional. Realizou-se uma seleção somente de discentes mulheres da UFABC, visando uma maior identificação do grupo, para verificar se este ambiente proporciona mais cumplicidade entre as alunas a ponto de se sentirem mais confortáveis em interagir e motivadas para a aprendizagem computacional. A seleção foi realizada através de preenchimento de formulário no qual se verificou o nível de conhecimento das alunas. Das 71 meninas inscritas, 40,8\% afirmaram não ter nenhum conhecimento sobre lógica de programação, 42,3\% afirmaram saber o que é lógica de programação, mas não como aplicá-la e somente $16,9 \%$ responderam que sabem o que é lógica e já sabem programar.

Além dessas estratégias de motivação, houve a preocupação de selecionar somente monitoras (estudantes do próprio curso, porém em estágio mais avançado) para ministrar o minicurso vislumbrando que esta escolha também seria importante para uma maior identificação das alunas. O material do minicurso utilizado foi elaborado inteiramente pelas monitoras com a revisão das professoras do $\mathrm{BCC}$, visando abordar o tema de forma lúdica. $\mathrm{O}$ objetivo foi demonstrar que a lógica está presente no cotidiano de todas e que a ela, junto à linguagem de programação, devem ser encaradas como a forma de escrever computacionalmente muitas destas atividades realizadas diariamente.

Dentre as 71 alunas inscritas, foram selecionadas 50 alunas e obteve-se 28 respostas confirmando a participação no minicurso, 12 respostas negativas à participação (nove por conflito de horário) e 10 não responderam. $\mathrm{O}$ minicurso foi ministrado em laboratórios da UFABC, equipados com computadores que foram utilizados individualmente por cada aluna. Utilizou-se a ferramenta VisualG para a parte de lógica de programação pois esta mostrou-se mais amigável para o primeiro contato na escrita de algoritmos. No entanto, numa segunda parte optou-se pela linguagem de programação Python para aprofundar as habilidades de programação. A metodologia utilizada envolveu aulas expositivas e práticas nas quais se explicava sobre determinado tema, demonstravam-se exemplos, realizavam-se exercícios em conjunto entre 
VII Congresso Brasileiro de Informática na Educação (CBIE 2018)

Anais dos Workshops do VII Congresso Brasileiro de Informática na Educação (WCBIE 2018)

monitoras e alunas e, por fim, exercícios práticos foram realizados individualmente pelas alunas com a supervisão e apoio das monitoras.

O minicurso chegou ao fim com 26 participantes e somente duas desistências. Ao término, foi aplicado um questionário online de forma anônima para verificar o nível de satisfação das alunas usando os mesmos parâmetros do questionário aplicado para inscrição. Após o minicurso, das 13 alunas que responderam o questionário, 92,3\% afirmaram saber o que é lógica de programação e como aplicá-la, enquanto $7,7 \%$ afirmaram conhecer lógica de programação, mas ainda não saber como aplicá-la.

Este segundo formulário também incluiu perguntas para verificar se o ambiente somente formado por mulheres fez diferença para o aprendizado das alunas, bem como sobre a confiança das meninas quanto a área de programação. Como apresentado na Figura 3, 92,3\% das alunas responderam que sentiram que faz diferença uma turma composta apenas por mulheres; e 76,9\% afirmaram estar confiantes sobre a área de programação, e demonstraram interesse em aprender mais sobre o assunto. Por fim, no formulário foi perguntado sobre o material desenvolvido para as aulas pelas monitoras que ministraram o curso. Das 13 meninas que responderam, 92,3\% afirmaram que o material estava claro e fácil de compreender e 7,7\% afirmaram que o material poderia ser melhorado. O material e recursos utilizados no laboratório se mostraram eficazes para o grupo de alunas selecionadas.

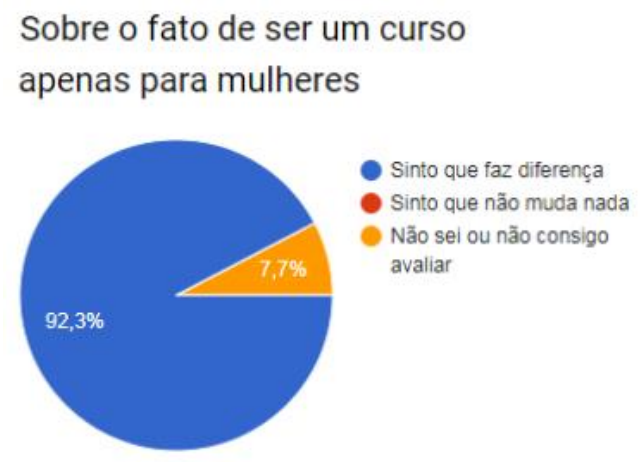

\section{Como você se sente em relação a área de programação}

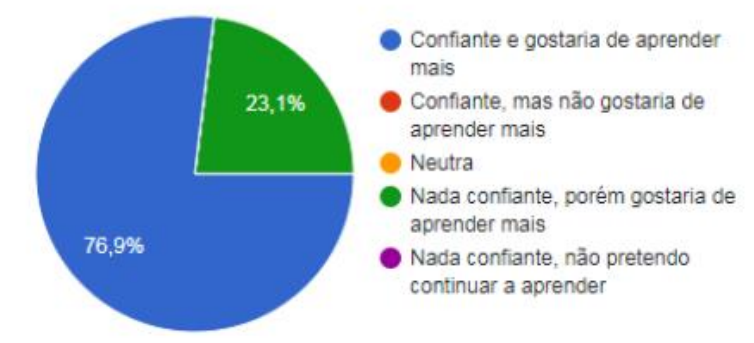

Figura 3. Algumas perguntas do questionário de satisfação e respostas.

Ao final do minicurso foi realizado um teste para avaliação do conhecimento adquirido através do jogo de tabuleiro Guerra em Alto Mar (Oliveira, 2017). O jogo contém perguntas de lógica de programação e Python, que exploram conhecimentos de variáveis, entrada e saída de dados, operadores lógicos e matemáticos, estruturas de repetição e condição, e funções. $O$ teste contou com a participação de 12 meninas divididas em equipes de três pessoas (ou seja, dois jogos simultâneos de uma equipe contra uma outra). Ao total, as meninas acertaram $88 \%$ das questões.

Todas as alunas que participaram do minicurso relataram que não obtiveram alfabetização computacional no ensino fundamental e médio e afirmaram que seria muito importante ter esta aprendizagem antes do ingresso à Universidade para que pudessem ter mais conhecimento sobre a computação e enxergá-la como uma opção universitária. Além disso, devido a participação no minicurso, elas pensam no BCC como possível escolha de curso pós BC\&T. A Figura 4 mostra parte dos comentários 
VII Congresso Brasileiro de Informática na Educação (CBIE 2018)

Anais dos Workshops do VII Congresso Brasileiro de Informática na Educação (WCBIE 2018)

registrados pelas alunas no formulário de avaliação final do curso, que ressaltam a importância da identificação, do estímulo e confiança na aprendizagem computacional ${ }^{3}$.

A ideia como um todo foi incrivel e vocês são ótimas, parabéns por tudo. Adoraria manter contato e aprender outras linguagens. Muito obrigada s2

O curso foi ótimo, acredito que deveria ter outras edições com o mesmo conteúdo eu só achei muito curto, gostaria de me aprofundar mais e aprender outras linguagens de programação.

Gostei muito do projeto e o curso vai me ajudar a continuar meus estudos individuais sobre data science com python.

Gostaria muito que o curso continuasse, em Python. Gostei muito, gostaria de parabenizá-las

Eu adorei a iniciativa! As instrutoras foram super gentis, didáticas e receptivas. Espero que cada vez mais meninas gostem de computação e sigam na área. Estou ansiosa para novas edições com outros cursos!

Muito obrigada pelo curso!!! meu professor meio louco passou java agora no primeiro quadrimestre e não explicou nada, porém as aulas de lógica que tive no curso, me ajudaram muuuuito. Obrigada de verdade, espero que mais meninas possam ter a oportunidade de participar desse curso maravilhoso, obrigada tb à todas as meninas, por sempre explicar com carinho e de forma atenciosa!! e tenho mto interesse em outros cursos, e em outras linguagens, e etc, se tiver, irei fazer com certeza, obrigada mais uma vez!!! <3 ps: Erika obrigada pelos docinhos, mimou muito a gente $<3<3<3$

Muito obrigada pelo curso!!! A ideia do projeto foi incrível, sempre quis aprender programação mas nunca soube por onde começar. Todas vocês foram muito atenciosas e ajudaram muito com todas as dúvidas, além dos mimos de chocolate em todas as aulas. Obrigada $<3$

Adoro vcs! Melhor mini-curso, espero muitos outros aaaaa

Meu profundo agradecimento pela oportunidade de aprender um pouco mais sobre esse assunto em um ambiente bem confortável

Figura 4. Alguns depoimentos registrados no questionário de satisfação.

\section{Algumas Reflexões da Equipe de Alunas do Projeto}

A tecnologia é um dos pilares da sociedade atual e é insustentável que um número tão pequeno de mulheres faça parte do grupo detentor desse conhecimento, responsável por criar soluções utilizadas diariamente por bilhões de pessoas. $\mathrm{O}$ que podemos perceber até agora é que a disparidade de gêneros encontrada em universidades é um reflexo de um processo que começa cedo e que contribui para que meninas descartem carreiras como a Computação. Esse processo se dá, entre outros aspectos, pela construção de estereótipos que definem atividades diferentes para meninas e meninos.

Sendo assim, é preciso, além de promover o ensino do pensamento computacional nas escolas, levar a pauta da necessidade de mulheres na tecnologia. Dessa forma, as meninas podem perceber que essa é uma carreira possível e que a participação delas nessa área pode contribuir de forma muito positiva para a sociedade, visto que equipes heterogêneas produzem melhores resultados e são mais criativas. A ação em escolas de ensino básico é de suma importância, pois muitas meninas desde pequenas não cogitam os cursos de computação, seja por desconhecimento da área, ou por considerá-la masculina, não se vendo ocupando tal espaço. O ensino do pensamento computacional também é uma oportunidade de mostrar que o cenário atual é bastante positivo para a inserção de mulheres na tecnologia, uma vez que diversas grandes

\footnotetext{
${ }^{3}$ Material e as respostas ao questionário disponíveis no site http://pesquisa.ufabc.edu.br/lirte/ctpm/curso/.
} 
VII Congresso Brasileiro de Informática na Educação (CBIE 2018)

Anais dos Workshops do VII Congresso Brasileiro de Informática na Educação (WCBIE 2018)

empresas do setor estão preocupadas com a baixa presença feminina em seu quadro de funcionários(as) e possuem iniciativas para mudar isso.

O ensino da lógica de programação nas escolas com foco no público feminino pode contribuir muito para reverter os dados apresentados anteriormente, visto que aprender essas habilidades durante a formação escolar pode ajudar para que elas se sintam mais seguras e à vontade com o universo da computação. Dessa forma, elas podem se sentir mais preparadas para entrarem em cursos superiores relacionados à Computação, o que pode levar tanto a um maior número de ingressantes como a um menor número de desistências e, portanto, o aumento das concluintes.

\section{Conclusões e Trabalhos Futuros}

Este artigo apresentou um projeto voltado para engajar meninas no curso de Ciência da Computação na UFABC alinhado com os objetivos ODS 4 e 5 da Agenda 2030 para o Desenvolvimento Sustentável da ONU. Nele foi realizada uma pesquisa sobre o desempenho das alunas nas disciplinas básicas de tecnologia e se afetaria seus interesses pela área de computação, refutando essa hipótese. Além disso, foram apresentadas estratégias de divulgação que serão ampliadas para abordar mais modelos femininos na computação, relatar experiências e aplicações práticas, bem como atingir um maior número de pessoas. Por fim, um curso de ensino de lógica de programação foi oferecido para alunas da graduação, e será ofertado para alunas do ensino médio da região usando ferramentas mais apropriadas (e.g. Gomes et al. 2014, Moreira et al. 2016). Todas as atividades do projeto (incluindo a escrita deste artigo) estão sendo protagonizadas pela equipe de oito alunas com a ajuda de cinco professoras.

Como trabalho futuro pretende-se ainda fomentar ações de mentoria, baseadas na promoção de interação entre alunas veteranas e ingressantes, para estimular a autoconfiança e ajuda mútua através de ações de aconselhamento, monitoria e apoio nas adversidades e desafios. Espera-se, com essa iniciativa, colocar em prática ideais como "juntas, somos mais fortes" e que o empoderamento feminino é responsabilidade das próprias mulheres, além de desmistificar a ideia de que mulheres competem umas com as outras. As pesquisas serão aprofundadas para avaliar de forma quantitativa e qualitativa o impacto do $++C \& T p M$ e analisar o cenário de gênero da UFABC em geral. Também se pretende promover discussões abertas a público interno e externo sobre o tema de desigualdade de gênero nas exatas e tecnologias. Ao todo, espera-se poder definir políticas e outras iniciativas que ajudem a aumentar a porcentagem de mulheres em todos os cursos específicos do BC\&T com menor representatividade feminina como, por exemplo, Matemática, Física e as Engenharias.

\section{Referências}

Bim, S., Figueiredo, K., Maciel, C. (2017) Por Mulheres na Computação no Brasil: análise das ações e publicações do evento Women in Information Technology. 9th LAWCC.

de Freitas Rodrigues, R., Nakamura, F., dos Santos, T.M., Lobo, L., Lauschner, T., Machado, A.L. (2017) Undergraduate women in Computing: where did they come from, how are they and where they are going? 9th LAWCC.

Gomes, W. F., Louzada, C. S., Nunes, M. A. S. N., Salgueiro, E. M., and Andrade, B. T. (2014). Incentivando meninas do ensino médio à área de Ciência da Computação 
VII Congresso Brasileiro de Informática na Educação (CBIE 2018)

Anais dos Workshops do VII Congresso Brasileiro de Informática na Educação (WCBIE 2018)

usando o Scratch como ferramenta. Anais do Workshop de Informática na Escola (WIE).

Grossi, M. G. R., Borja, S. D. B., Lopes, A. M., Andalécio, A. M. L. (2016). As mulheres praticando ciência no Brasil. Revista Estudos Feministas, 24(1), 11-30.

Holanda M., Dantas M., Couto G., Correa J. M., A. de Araújo P.F., Walter M. E. T. (2017) Perfil das Alunas no Departamento de Computação da Universidade de Brasília. 11th WIT.

Maciel, C., Bim, S. A. (2017). Programa Meninas Digitais - ações para divulgar a Computação para meninas do ensino médio. Anais do Computer on the Beach, 327-336.

Maia, Marcel Maggion. (2016). Limites de gênero e presença feminina nos cursos superiores brasileiros do campo da computação. Cadernos Pagu. n. 46, pp. 223-244.

Microsoft Corp. (2017). Why Europe's girls aren't studying STEM. Microsoft Philanthropies. Disponível em http://bit.ly/2qiFT5u. Acesso em outubro de 2018.

Monard M. C., Fortes R.P. (2013) Uma visão da participação nos cursos de Ciência da Computação no Brasil. 6th LAWCC.

Monteiro R. S., Marinho J. M. P., Braga R. B., Viana M. N., de Oliveira C. T. (2017). Delineando o Perfil Feminino Discente do Bacharelado em Ciência da Computação do IFCE campus Aracati. 11th WIT.

Moreira, J., Mattos, G., Barreto, L., Cavaco, I., Moreira, R. (2016). Atraindo Meninas para a Ciência da Computação: Métodos e Ferramentas. WALGPROG. Anais dos Workshops do CBIE.

Nakamura, F., Santos, T., de Freitas Rodrigues, R., Lauschner, T. (2017) Brazilian High School Girls: What Drives Their Career Choices? 9th LAWCC.

Nakamura F., Lobo L., Freitas R., Almeida T., Machado A. L., Lauschner T. (2017). Participação feminina em cursos de computação: um estudo no Instituto de Computação da Universidade Federal do Amazonas. 11th WIT.

Nunes, M.A.S.N., Louzada, C.S., Salgueiro, E.M., Andrade, B.T., Lima, P.S., Figueiredo, R.M.C.T. (2016) Mapeamento de iniciativas brasileiras que fomentam a entrada de mulheres na computação. 10th WIT.

Oliveira, R.N.R. (2017). Guerra em Alto Mar: Relatando a Construção de um Jogo de Tabuleiro para a Área de Educação em Computação. Trabalho de conclusão de curso (Licenciatura em Ciência da Computação), UFPB, Rio Tinto.

UNESCO. (2018). Decifrar o código: educação de meninas e mulheres em ciências, tecnologia, engenharia e matemática (STEM). Disponível em http://www.unesco.org/new/pt/brasilia/about-this-office/single-

view/news/portuguese version_of cracking the code girls and womens. Acesso: outubro de 2018.

UFABC (2017) Projeto Pedagógico Institucional. Disponível em http://www.ufabc.edu.br/images/imagens a ufabc/projeto-pedagogicoinstitucional.pdf. Acesso: outubro de 2018. 